\section{Predators and Cranks}

\author{
M. Castillo, Editor-in-Chief
}

A few years ago I received an e-mail invitation to write a review article on MR spectroscopy from a journal I did not know. Thinking that it was a good project for one of my visiting research fellows, I accepted. It took us about 3 months to write and illustrate the article, and when we submitted it, we signed, as is commonly done, their copyright agreement. Much to my surprise, we shortly thereafter received an invoice for US $\$ 2700$ because this journal operated under the "open access" model. Paying that much would have used much of my "book and travel" allowance, so we retracted the publication only to find that retractions were impossible! After much back and forth and threatening to get the University's lawyers involved, they returned the article to us (it was later published in the Neuroimaging Clinics, a bona fide journal, not open access). While there is nothing wrong with open access and the American Journal of Neuroradiology (AJNR) supports it as long as our current financial model remains stable, it is a system ripe for abuse by many.

In April 2013, the New York Times (NYT) published a piece on "predatory" medical journals and scientific meetings. ${ }^{1}$ It described how a group of scientists were duped into participating at a meeting that initially seemed legitimate (see below). Welcome to the world of "pseudoacademia," where newly created outfits recruit speakers and authors strictly for profit in activities that are not linked to any respectable scientific society, group, or journal.

There are currently hundreds of companies that "sponsor" meetings and journals under the rubric of "open access." The open access movement arose from the need to share information with all of those who are interested in it while trying to avoid paying for subscriptions or buying individual articles, especially if these sprang from investigations financed by public funds. Although controversial, open access makes articles easier to find and quote and is thus beneficial to authors and readers alike. There are legitimate, prestigious open access journals such as ones published by the Public Library of Science, which rightly demand a fee for publication. Predatory publishers take advantage of the open access movement and of our never-ending hunger to fill our resumes and be promoted and have developed journals that closely resemble genuine ones. In September these fraudulent activities hit home when many of us received an e-mail message from Ivy Union Publishing Company (a well-known publisher of predatory journals) recruiting editorial board members for the new AJNR (American Journal of Neuroscience Research). The e-mail was designed in blue tones similar to those used by our AJNR, and even the font used was exactly the same as the one in our previous cover design. Immediately we contacted our lawyers, who sent a letter to Ivy Union Publishing demanding that they cease to use our trademark, to which, not surprisingly, we have yet to receive a response.

http://dx.doi.org/10.3174/ajnr.A3774
Jeffrey Beall, an academic librarian at the University of Colorado, has created a list of predatory journals (commonly known as "Beall's list") and their publishers. ${ }^{2} \mathrm{Mr}$ Beall divides these publications into those questionable publishers that have portfolios of up to hundreds of journals (the Ivy Union Publishing Web site had 131 pages of journal titles when I looked at it) and individual journals published outside traditional platforms. Before submitting an article to a new journal, Mr Beall suggests that one checks his list of criteria for determining predatory open access journals and publishers found at http://scholarlyoa.com/2012/11/30/ criteria-for-determining-predatory-open-access-publishers-2ndedition. Briefly, any of the following should steer one away from submitting articles to a journal:

1) The name of the journal is incompatible with its scope.

2) Its national base is not clear.

3) Submission-to-publication periods are incompatible with traditional peer review (my comment: less than 21 days is suspicious).

4) No clear editor and no editorial board.

5) No Impact Factor listed.

6) Unprofessional, hastily put together Web site.

7) No mention of fees until an article has been accepted.

Today, there are more than 4000 predatory journals that publish $10 \%-15 \%$ of all open access articles. Not only are they tricking authors into submitting and paying for their articles, they offer members of their editorial boards as much as $20 \%$ of the author fees. Once you become a member of one of these editorial boards, it is basically impossible to be removed as several anecdotes in the NYT article recount. ${ }^{1}$ Needless to say, Mr Beall is being sued by several of these publishers, has been a victim of vicious on-line comments, and is the subject of Internet campaigns to discredit him. ${ }^{3}$

Because rapidly developing economies are generating a significant number of new researchers, most "open access" publishers are springing up there, but their Web sites manipulate the truth to appear as if they are headquartered in the United States, United Kingdom, Australia, or Canada (though no contact information is found on the Ivy Union Publishing Web site, our investigation led to an address in Delaware, which then led us to an address in Boston). The geographic bases of predatory journals can be found on Semantico.com. Data there show that by plugging the IP addresses of 192 predatory journals and 321 predatory publishers into a geolocator, one finds that $65 \%$ of such journals and $67 \%$ of publishers were registered in the United States. Because one can never be sure whether the locations linked to the addresses are real or fake, it is always possible that indeed these publications actually started in the United States.

Predatory journals care little about the quality of science and are known to sometimes publish plagiarized work. ${ }^{4}$ Their articles receive little professional formatting to save costs, and they are never listed in the larger citation databases such as PubMed, Web of Science, or Scopus; a fact that nullifies their open access spirit because they are very hard to find and quote. Sometimes, predatory journals even publish articles without the author's permis- 
sion. Many of these journals offer to translate their articles into 50 different languages, when, in reality, this feature only directs the readers to use the free Google Translate service for this purpose.

A glaring example of types of peer review and acceptances carried out by predatory journals is illustrated by the following hoax. Two well-regarded professionals utilized SClgen (http:// pdos.csail.mit.edu/scigen), a computer program that generates nonsensical articles dealing with computer science, to create an article that was submitted to a predatory journal called The Open Information Science Journal. ${ }^{5}$ The authors even gave their affiliation as the Center for Research in Applied Phrenology (CRAP)! After the article was accepted, they received a bill for US $\$ 800$ to be sent to a PO Box located in the United Arab Emirates. However, to be fair, SClgen was also used to generate a similar article that was submitted and accepted by a reputable journal published by Elsevier.

The problem gets worse, and the lines, blurrier. Between 2000 and 2005, publishing giant Elsevier published 6 fake medical journals, all sponsored by pharmaceutical companies, and as if that was not bad enough, these journals often contained reprinted articles that were favorable to products manufactured by the sponsoring companies. ${ }^{6}$ Immediately after this was publicly disclosed, the CEO of Elsevier's Health Sciences Division issued an apology and a reassurance that this would not occur any more.

All of the above also extends to congresses and meetings. In the previously mentioned NYT article, ${ }^{1}$ researchers were tricked into presenting at a meeting called "Entomology-2013" when they thought they were presenting at the well-recognized and prestigious "Entomology 2013" (do you see the difference in the titles?). Later they were charged for participating at the meeting. Last month I received an invitation to participate in the 1st International Conference of Radiology to be held in Raleigh, North Carolina (just 30 miles away from where I live). The invitation that came from some outfit located in China promised me time at the podium, dinners, "mingling" with the best researchers, and a name badge that would clearly identify me as a prominent participant and world expert. When I did not respond, I was bombarded with spamlike e-mail messages asking me to confirm my participation.

These so-called "crank" meetings promise luminary speakers who often do not have enough valid publications to support this denomination or simply have not published their research. ${ }^{7}$ To me, it is not clear who attends and who lectures; I do not know anyone who has.

One of the best known crank meetings is Autism One (which is held in Canada and the United States). ${ }^{7}$ In it, researchers of dubious integrity give talks, and the main speaker is generally Jenny
McCarthy. Ms McCarthy, a former Playboy Playmate, is a popular television show host and author of books on parenting, alternative medicine, and autism. Other guest speakers generally have published their results in blogs and popular media and, at best, in predatory journals. Unfortunately, serious institutions such as the University of Toronto, the Sick Kids Foundation, and even the American Academy of Pediatrics have been suckered into debacles stirred by presentations at these autism meetings.

I urge you to look in your own backyard for predators. Many institutional libraries, when choosing journal subscriptions, have rules that force them to buy those under the categories of "Gold or Green Open Access" (one archives the articles for the authors; in the other, the authors themselves archive the articles) or those that adhere to the Creative Commons license agreement. Gold or green has nothing to do with paying to get published, just with access. Most predatory journals claim to be gold or green to make themselves attractive to libraries. Like true predators, these journals stay around just while there is prey. Anecdotally, I heard that a predatory publisher abruptly closed its doors (and Web site) once its profits reached US $\$ 100$ million. Beware, because predatory journals will take away not only your money but, more important, your prestige, reputation, and self-respect.

\section{REFERENCES}

1. Kolata G. Scientific articles accepted (personal checks, too). New York Times. April 7, 2013. http://www.nytimes.com/2013/04/08/ health/for-scientists-an-exploding-world-of-pseudo-academia. html?pagewanted=all\&_r=0. Accessed September 16, 2013

2. Beall's list of predatory, open-access publishers. http://www.academia. edu/1151857/Bealls_List_of_Predatory_Open-Access_Publishers. Accessed September 16, 2013

3. Butler D. Investigating journals: the dark side of publishing. Nature 2013;445. http://www.nature.com/news/investigating-journals-thedark-side-of-publishing-1.12666. Accessed September 16, 2013

4. Sanchez J. Predatory publishers are corrupting open access. Nature 2012;489. http://www.nature.com/news/predatory-publishers-arecorrupting-open-access-1.11385. Accessed September 16, 2013

5. Aldhous P. CRAP paper accepted by journal. New Scientist 2009. http://www.newscientist.com/article/dn17288-crap-paper-acceptedby-journal.html\#.Ujc7HD-Jnq5. Accessed September 16, 2013

6. Grant B. Elsevier published 6 fake journals. The Scientist 2009. http://www.the-scientist.com/?articles.view/articleNo/27383/title/ Elsevier-published-6-fake-journals. Accessed September 16, 2013

7. Gorski D. Crank "scientific" conferences: a parody of science-based medicine that can deceive even reputable scientists and institutions. Science-Based Medicine 2009. http://www.sciencebased medicine.org/crank-conferences-a-parody-of-science-basedmedicine-that-can-suck-in-even-reputable-scientists-and-institutions. Accessed September 16, 2013 